\title{
Azacitidine in 302 patients with WHO-defined acute myeloid leukemia: results from the Austrian Azacitidine Registry of the AGMT-Study Group
}

\author{
Lisa Pleyer • Sonja Burgstaller • Michael Girschikofsky • Werner Linkesch • \\ Reinhard Stauder • Michael Pfeilstocker • Martin Schreder • Christoph Tinchon • \\ Thamer Sliwa • Alois Lang • Wolfgang R. Sperr • Peter Krippl • Dietmar Geissler • \\ Daniela Voskova • Konstantin Schlick • Josef Thaler • Sigrid Machherndl-Spandl • \\ Georg Theiler • Otto Eckmüllner • Richard Greil
}

Received: 8 April 2014 / Accepted: 29 May 2014 / Published online: 21 June 2014

(C) The Author(s) 2014. This article is published with open access at Springerlink.com

\begin{abstract}
Data on efficacy and safety of azacitidine in acute myeloid leukemia (AML) with $>30 \%$ bone marrow (BM) blasts are limited, and the drug can only be used off-label in these patients. We previously reported on the efficacy and safety of azacitidine in 155 AML patients treated within the
\end{abstract}

Electronic supplementary material The online version of this article (doi:10.1007/s00277-014-2126-9) contains supplementary material, which is available to authorized users.

L. Pleyer $(\bowtie) \cdot$ K. Schlick $\cdot$ R. Greil $(\bowtie)$

3rd Medical Department with Hematology and Medical Oncology, Hemostaseology, Rheumatology and Infectious Diseases, Laboratory for Immunological and Molecular Cancer Research, Oncologic Center, Paracelsus Medical University Hospital Salzburg, and Center for Clinical Cancer and Immunology Trials at Salzburg Cancer Research Institute, Müllner Hauptstrasse 48, 5020 Salzburg, Austria e-mail: 1.pleyer@salk.at

e-mail: r.greil@salk.at

\section{S. Burgstaller $\cdot$ J. Thaler}

Department for Internal Medicine IV, Hospital Wels-Grieskirchen, Wels, Austria

M. Girschikofsky $\cdot$ S. Machherndl-Spandl

1st Medical Department with Hematology, Stem Cell

Transplantation, Hemostatsis and Medical Oncology, Elisabethinen

Hospital, Linz, Austria

W. Linkesch $\cdot$ G. Theiler

Department of Hematology, Medical University, Graz, Austria

R. Stauder

Internal Medicine V (Hematology and Oncology), Innsbruck

Medical University, Innsbruck, Austria

M. Pfeilstocker

Third Medical Department, Hanusch Hospital, Vienna, Austria
Austrian Azacitidine Registry (clinicaltrials.gov identifier NCT01595295). We herein update this report with a population almost twice as large $(n=302)$. This cohort included 172 patients with $>30 \%$ BM blasts; $93 \%$ would have been excluded from the pivotal AZA-001 trial (which led to

M. Schreder

First Department of Internal Medicine, Center for Oncology and Hematology, Wilhelminenspital, Vienna, Austria

C. Tinchon

Department for Hematology and Oncology, LKH Leoben-Eisenerz, Leoben, Austria

T. Sliwa

5th Medical Department with Oncology und Palliative Medicine, Hietzing, Vienna, Austria

A. Lang

Internal Medicine, Hospital Feldkirch, Feldkirch, Austria

W. R. Sperr

Division of Hematology and Hemostaseology, Department of Internal Medicine I, Medical University of Vienna, Vienna, Austria

P. Krippl

Department for Internal Medicine, LKH Fuerstenfeld, Fuerstenfeld, Austria

D. Geissler

Department for Internal Medicine, with Nephrology, Gastroenterology and Hepatology, Hematology and Medical Onkology, Intensive Care Unit, and Rheumatology, Klinikum Klagenfurt am Wörtersee, Pörtschach am Wörthersee, Austria 
European Medicines Agency (EMA) approval of azacitidine for high-risk myelodysplastic syndromes (MDS) and AML with $20-30 \%$ BM blasts). Despite this much more unfavorable profile, results are encouraging: overall response rate was $48 \%$ in the total cohort and $72 \%$ in patients evaluable according to MDS-IWG-2006 response criteria, respectively. Median OS was 9.6 (95\% CI 8.53-10.7)months. A clinically relevant OS benefit was observed with any form of disease stabilization (marrow stable disease (8.1 months), hematologic improvement (HI) (9.7 months), or the combination thereof (18.9 months)), as compared to patients without response and/ or without disease stabilization (3.2 months). Age, white blood cell count, and BM blast count at start of therapy did not influence OS. The baseline factors LDH $>225$ U/1, ECOG $\geq 2$, comorbidities $\geq 3$, monosomal karyotype, and prior disease-modifying drugs, as well as the response-related factors hematologic improvement and further deepening of response after first response, were significant independent predictors of OS in multivariate analysis. Azacitidine seems effective in WHO-AML, including patients with $>30 \% \mathrm{BM}$ blasts (currently off-label use). Although currently not regarded as standard form of response assessment in AML, disease stabilization and/or HI should be considered sufficient response to continue treatment with azacitidine.

Keywords Austrian Azacitidine Registry · Azacitidine . AML $\cdot$ Overall survival $\cdot$ Prognostic factors $\cdot$ Bone marrow blasts

\section{Introduction}

Acute myeloid leukemia (AML) is an aggressive disease with an unfavorable prognosis $[1,2]$. Treatment with curative potential, i.e., conventional chemotherapy and/or allogeneic stem cell transplantation, is rarely an option for elderly patients due to high age, comorbidities, poor performance status, and/or adverse cytogenetics. Azacitidine is approved for AML with $20-30 \%$ bone marrow (BM) blasts. Approval was based on the pivotal AZA-001 trial [3, 4]. Currently, the 001-followup trial (clinicaltrials.gov identifier NCT01074047) is underway with the same design, but limited to patients with $>30 \%$ $\mathrm{BM}$ blasts, with the aim to widen the indication of azacitidine to AML patients as defined by WHO, i.e., irrespective of BM blast count. Until the results of this trial become available,

\section{Voskova}

Internal Medicine 3, Center for Hematology and Medical Oncology, General Hospital-Linz GesmbH, Linz, Austria

O. Eckmüllner

Institut für Waldwachstumsforschung, Universität für Bodenkultur,

Vienna, Austria treatment of AML patients with more than $30 \%$ BM blasts with azacitidine remains an off-label use.

We previously reported on the use, efficacy, and safety of azacitidine in 155 WHO-AML patients treated in a real-life setting. We herein update this report with a population almost twice as large $(n=302)$. The aim of the current publication was to potentially confirm, consolidate, and validate our previous results. The primary endpoint was evaluation of efficacy (i.e., response) of azacitidine in patients with AML defined according to WHO criteria (including patients with $>30 \% \mathrm{BM}$ blasts). The secondary endpoints were safety (i.e., toxicity and adverse events), overall survival (OS), and statistical analysis of factors known or thought to influence overall survival in order to establish prognostic markers (Table 1 [4-14]).

\section{Patients, design, and methods}

Between February 2009 and October 2013, 302 AML patients from 14 specialized centers for hematology and medical oncology in Austria were included. Data cleaning/survival analysis cutoff date was 21 January 2014. The sole inclusion criteria were the diagnosis of WHO-AML and treatment with at least one dose of azacitidine. No formal exclusion criteria existed, as the aim was to include all AML patients treated with azacitidine, irrespective of age, comorbidities, and/or number of previous lines of treatment. Informed consent to allow the collection of personal data was obtained for all retrospectively documented patients who were alive, as well as for all prospectively included patients.

Registry design, data collection and monitoring, as well as assessment of efficacy, safety and endpoints within the Austrian Azacitidine Registry were performed as previously described $[8,15]$.

Overall response was defined as complete response (CR), marrow complete response (mCR), partial response (PR) (as defined by commonly used AML response criteria [16]), and hematologic improvement (HI) (as defined by the IWG-MDS2006 response criteria [17]). Marrow stable disease (mSD) was defined as failure to achieve at least PR, but no evidence of progressive disease (PD) for $>8$ weeks. PD was defined as any of the following: (i) $\geq 50 \%$ decrement from maximum remission/response in granulocytes or platelets, (ii) reduction in hemoglobin by $2 \mathrm{~g} / \mathrm{dl}$, (iii) transfusion dependence [17].

OS was assessed using the Kaplan-Meier method. Univariate analyses were performed with log-rank tests. Cox regression stratified on the various factors was used for analyses of risk factors for OS. Baseline characteristics were compared by nonparametric tests (Chi-squared test for qualitative variables, Wilcoxon test for quantitative variables). For multivariate analysis, logistic regression according to the Wald method with forward stepwise selection (entry level 0.05 ; level for keeping the variable 0.051) was used. Univariate analyses 


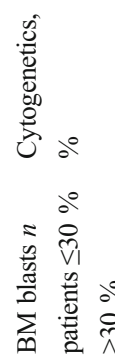

울

Eิ

융 है 표

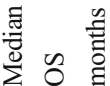

皱层

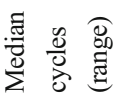

遂

过

过

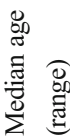

递

度言

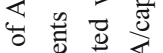

宅镸导

䔍

峁主

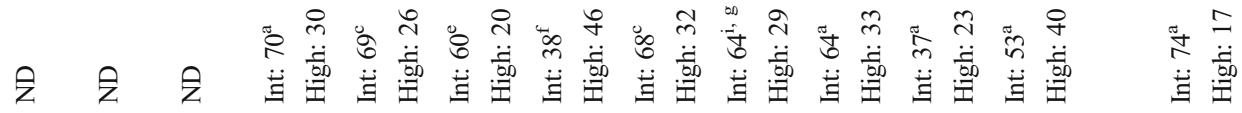

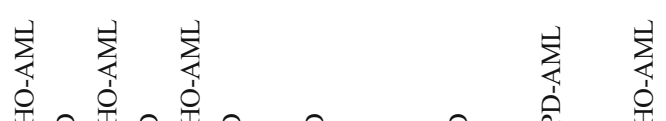

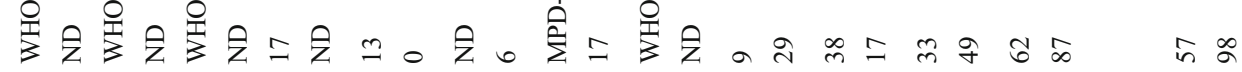

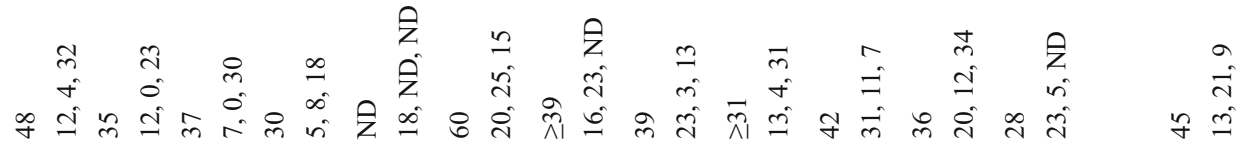

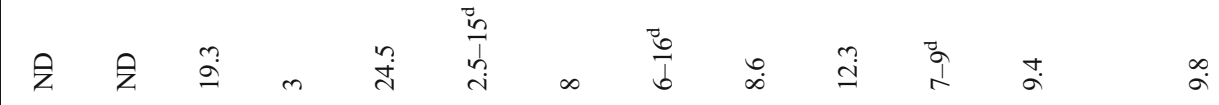

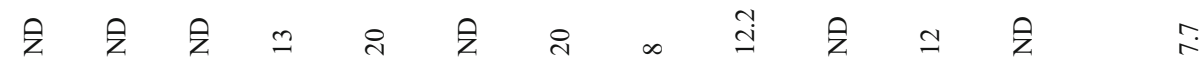

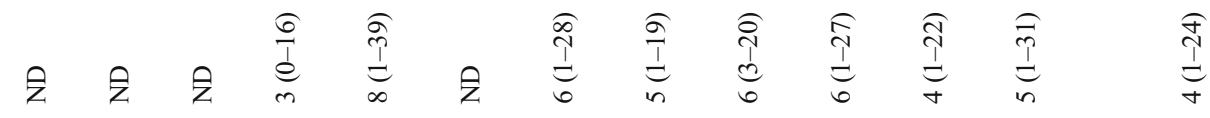

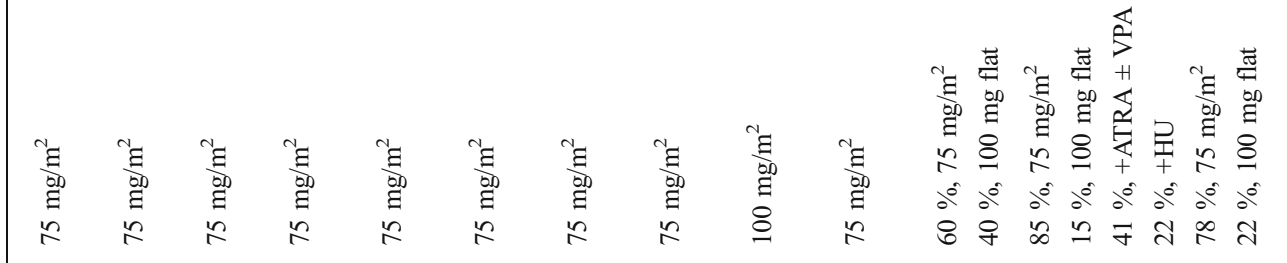

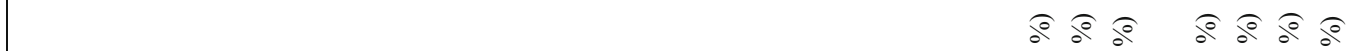

I I I $I$ I I I I $p$ I I

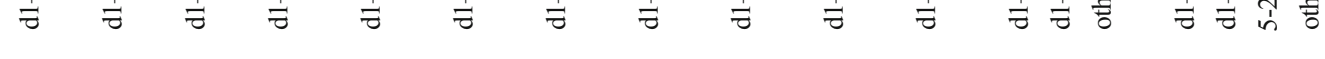

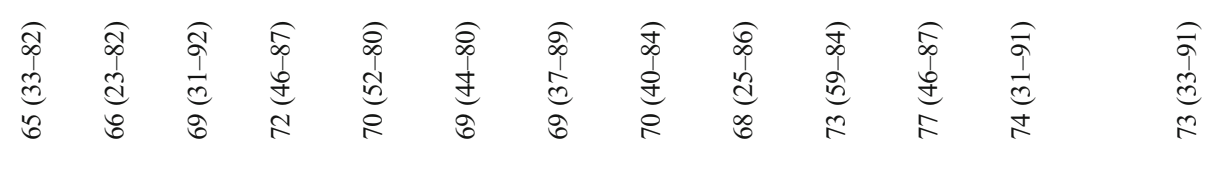

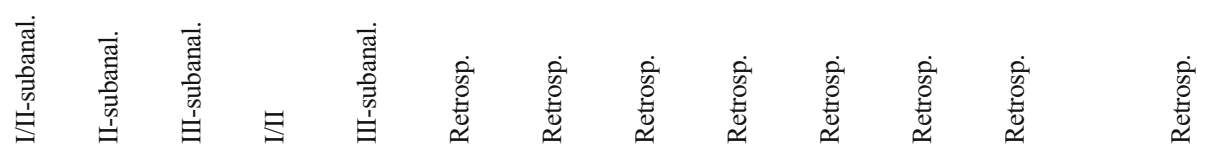

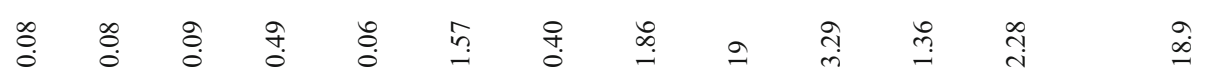

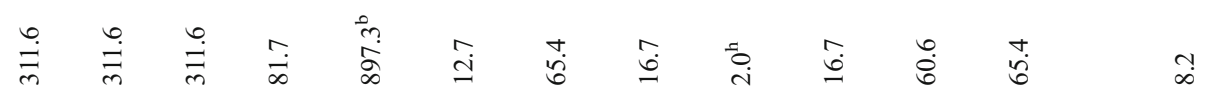

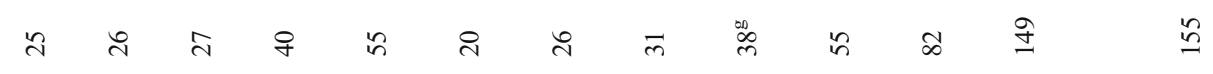

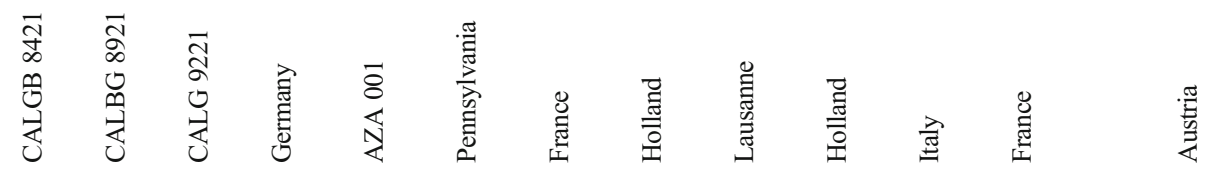




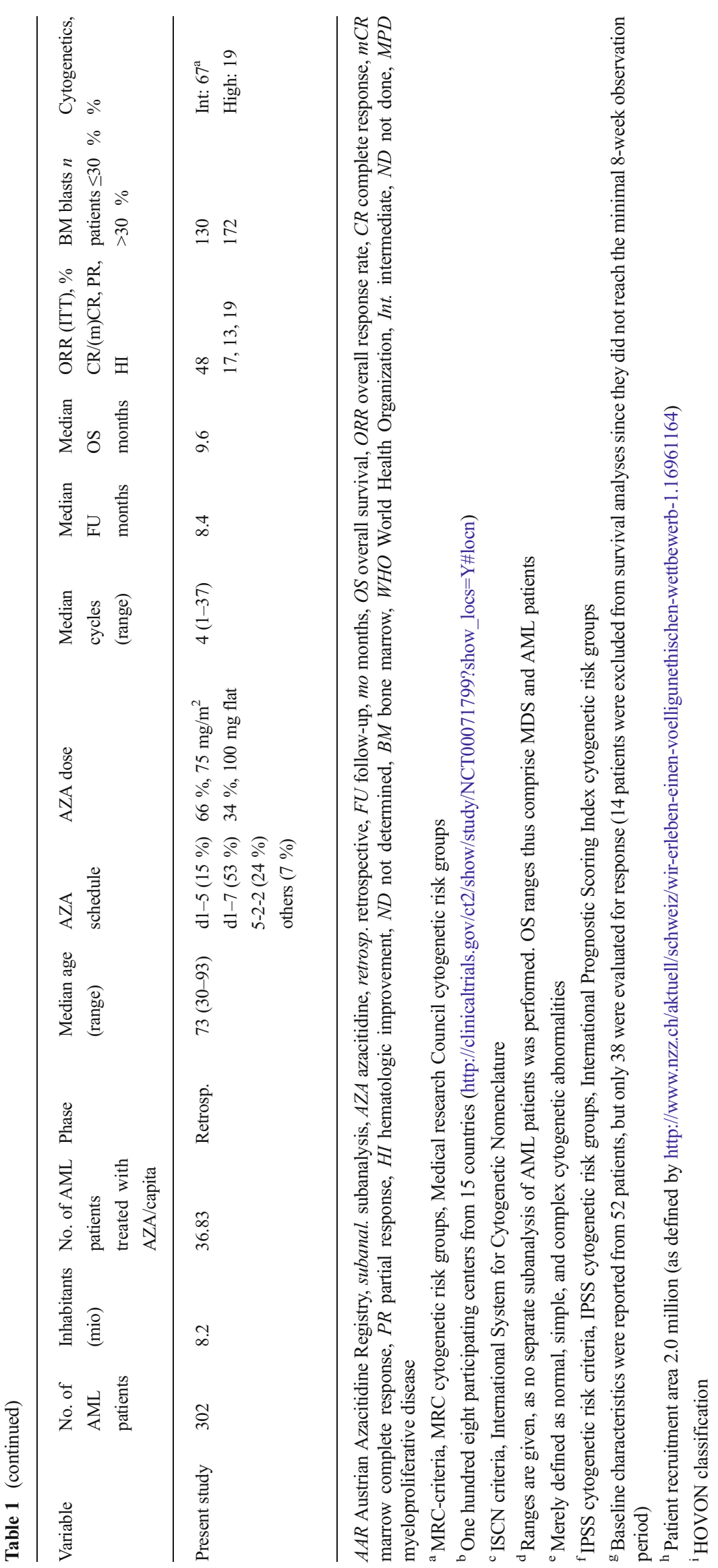


were performed and confirmed by two independent statisticians [H.A., O.E.]. The confirmed results were the basis for multivariate analysis. All variables with $p<0.05$ in univariate analyses were included in multivariate analysis, except for those cases, where parsimony would have been disrupted due to redundancy in the variables. Analyses were performed with SPSS. No adjustments were made for multiple testing.

\section{Results}

Patient characteristics

Patient baseline characteristics at azacitidine treatment start can be taken from Table 2. Median age was 73 (range 30-93); $43 \%$ of patients were older than $75,21 \%$ were older than 80 , and $8 \%$ were older than 85 years, respectively; 172 patients (57\%) had $>30 \%$ BM blasts; $19 \%$ had an unfavorable karyotype, and $67 \%$ had an intermediate karyotype according to MRC criteria [18]. In the absence of consensus for cytogenetic classification of AML in the elderly [4, 19], we additionally assessed the IPSS cytogenetic risk categories [20] (Table 2).

\section{Treatment modalities}

Azacitidine was administered as first-line treatment in $46 \%$ of patients; $46 \%$ of patients received azacitidine after insufficient response to, or early relapse after, conventional chemotherapy/allo-SCT (32\%), or other disease modifying treatment (14\%); the remaining patients received azacitidine either as bridging to allogeneic stem cell transplantation (alloSCT) (3\%) or as maintenance treatment after CR to chemotherapy ( $4 \%$ ). Azacitidine was not always first-line therapy, but also second-, third-, fourth-, fifth-, or last-line therapy for a relevant proportion of our patients: $28 \%$ had received more than one line of conventional chemotherapy prior to azacitidine (Table 2).

A median number of 4 (range 1-37) azacitidine courses were given. Most patients $(85 \%)$ received the drug subcutaneously (average dose/cycle, $846 \mathrm{mg}$ ), $10 \%$ intravenously (average dose/cycle, $815 \mathrm{mg}$ ), and in $5 \%$ both applications forms were used (average dose/cycle, $831 \mathrm{mg}$ ); $77 \%$ of patients predominantly received 7 days of azacitidine $(53 \%$ European Medicines Agency (EMA)-approved d1-7 (median dose/cycle, $924 \mathrm{mg}$ ), $24 \%$ 5-2-2 (median dose/cycle, $910 \mathrm{mg}$ )) (Supplemental Table 1). EMA-approved azacitidine target dose $\left(75 \mathrm{mg} / \mathrm{m}^{2} \times 7 \pm 10 \%\right)$ was reached in $33 \%$ of applied cycles; 349/2013 (17\%) of all cycles were administered as "flat" dosage (i.e., $100 \mathrm{mg}$ azacitidine/cycle-day; median dose/cycle, $700 \mathrm{mg}$ ). Hospitalization for the sole reason of azacitidine application occurred in $47 \%$ of cycles at the discretion of the treating physician, mainly due to
Table 2 Baseline characteristics at azacitidine treatment start

\begin{tabular}{|c|c|}
\hline Median age, years (range) & $73(30-93)$ \\
\hline Gender, male, $n(\%)$ & $175(57.9)$ \\
\hline \multicolumn{2}{|l|}{ WHO diagnosis, $n(\%)^{\mathrm{a}, \mathrm{b}}$} \\
\hline t-AML & $24(7.9)$ \\
\hline AML-RCA ${ }^{\mathrm{c}} /$ gene mutations $^{\mathrm{d}}$ & $61(20.2)$ \\
\hline AML-RCA & $13(4.3)$ \\
\hline AML with gene mutations & $52(17.2)$ \\
\hline AML-MRF & $203(67.2)$ \\
\hline AML-MRC & $75(22.2)$ \\
\hline AML with antecedent hematologic disease & $89(29.5)$ \\
\hline Antecedent MDS & $60(19.9)$ \\
\hline Antecedent CMML & $11(3.6)$ \\
\hline Antecedent CMPD & $18(6.0)$ \\
\hline AML with myelodysplasia (MLD) & $173(57.3)$ \\
\hline AML-NOS & $61(20.2)$ \\
\hline \multicolumn{2}{|l|}{ Peripheral blood blasts, $n(\%)$} \\
\hline No data & $14(4.6)$ \\
\hline $0 \%$ & $101(33.4)$ \\
\hline$>0 \%$ & $187(61.9)$ \\
\hline Median (range), $\%$ & $3.5(0-97)$ \\
\hline \multicolumn{2}{|l|}{ Bone marrow blasts, $n(\%)$} \\
\hline$<20 \%{ }^{\mathrm{e}}$ & $51(16.9)$ \\
\hline $20-30 \%$ & $79(26.2)$ \\
\hline$>30 \%$ (off-label use) & $172(57.0)$ \\
\hline Median (range), $\%$ & $32(0-98)$ \\
\hline \multicolumn{2}{|l|}{ WBC count, $n(\%)$} \\
\hline$<10 \mathrm{G} / 1$ & $150(49.7)$ \\
\hline$\geq 10 \mathrm{G} / 1$ & $61(20.2)$ \\
\hline$\geq 15 \mathrm{G} / 1$ & $40(13.2)$ \\
\hline$\geq 20 \mathrm{G} / 1$ & $29(9.6)$ \\
\hline$\geq 30 \mathrm{G} / 1$ & $15(5.0)$ \\
\hline$\geq 50 \mathrm{G} / 1$ & $7(2.3)$ \\
\hline
\end{tabular}

Transfusion dependence, $n(\%)$

Any type of TD

$183(60.6)$

RBC-TD

$175(57.9)$

PLT-TD

$113(37.4)$

RBC-TD + PLT-TD

$105(34.8)$

IPSS cytogenetic risk, $n(\%)$

Not evaluable

$33(10.9)$

Good

$161(53.3)$

55 (18.2)

$53(17.5)$

Poor

$33(10.9)$

$11(3.6)$

Good

$201(66.6)$

Intermediate

$57(18.9)$

Specific chromosomal aberrations, $n(\%)$

Not evaluable/not evaluated

Normal karyotype 
Table 2 (continued)

\begin{tabular}{l} 
Median age, years (range) \\
\hline Specific aberrations $^{\mathrm{b}}$ \\
Complex karyotype \\
Monosomal karyotype \\
MK only \\
MK and complex \\
$-5 \mathrm{q}$ \\
-7 \\
$-7 \mathrm{q}$ \\
+8 \\
$-20 \mathrm{q}$ \\
$-\mathrm{Y}$ \\
Others
\end{tabular}

Molecular diagnostics ${ }^{\mathrm{b}}, n(\%)$

Not done/no data

Normal

FLT3

NPM1

$\mathrm{nv}(16)$

Others

Comorbidities $^{\mathrm{b}}, n(\%)$

Cardiac $^{\mathrm{e}}$

Renal insufficiency

Diabetes mellitus

Solid tumor

Liver disease

Pulmonary

Hematologic neoplasm ${ }^{\mathrm{f}}$

Thromboembolic episodes

Infection

Obesity (BMI $>35 \mathrm{~kg} / \mathrm{m}^{2}$ )

Cerebrovascular disease

Psychiatric disturbance (requiring consult/treatment)

Rheumatologic

Peptic ulcer (requiring treatment)

Inflammatory bowel disease

Number of comorbidities, $n(\%)$

0

1

2

3

$>3$

$\mathrm{ECOG} \geq 2, n(\%)$

HCT-CI, $n(\%)$

Low risk

Int. risk

High risk

Treatment prior to $\mathrm{AZA}^{\mathrm{g}}, n(\%)$

None

Growth factors and/or iron chelators
$73(30-93)$

$120(39.7)$

$31(10.3)$

32 (10.6)

$6(2.0)$

$26(8.6)$

33 (10.9)

$25(8.3)$

17 (5.6)

$26(8.6)$

5 (1.7)

8 (2.6)

79 (26.2)

$148(49.0)$

89 (29.5)

43 (14.2)

36 (11.9)

4 (1.3)

$91(30.1)$

$124(41.5)$

54 (17.9)

54 (17.9)

41 (13.6)

35 (11.6)

33 (10.9)

31 (10.3)

$28(9.3)$

28 (9.3)

25 (8.3)

25 (8.3)

20 (6.6)

11 (3.6)

8 (2.6)

3 (1.0)

$62(20.5)$

$90(29.8)$

73 (24.2)

43 (14.2)

34 (11.3)

73 (24.2)

$93(30.8)$

117 (38.7)

$92(30.5)$

115 (38.1)

24 (7.9)
Table 2 (continued)

Median age, years (range)

$73(30-93)$

Prior disease modifying treatment

$163(54.0)$

Treatment prior to $\mathrm{AZA}^{\mathrm{b}}, n(\%)$

None

$115(38.1)$

Erythropoietin stimulating agents

$23(7.6)$

G-CSF

$34(11.3)$

Thrombopoietin-stimulating agents

$2(0.7)$

Iron chelation therapy

$12(4.0)$

Thalidomide

5 (1.7)

Lenalidomide

$11(3.6)$

ATG, CyA

4 (1.3)

Low-dose cytarabine

Intensive chemotherapy for MDS/AML

$125(41.4)$

Chemotherapy for other neoplasm

$22(7.3)$

Hydroxyurea

$26(8.6)$

Others

Reason for treatment, $n(\%)$

1st line treatment ${ }^{\mathrm{h}}$

$139(46.0)$

Bridging to allo-SCT

$10(3.3)$

Maintenance after CR to CTX

$13(4.3)$

No CR to conventional chemotherapy/allo-SCT

$98(32.5)$

No CR to other disease modifying treatment

$42(13.9)$

$t$ - $A M L$ treatment-related AML, $A M L-R C A$ AML with recurrent cytogenetic abnormalities, $A M L-M R F$ AML with MDS-related features, $C M P D$, chronic myeloproliferative disease, $A M L-N O S$ AML not otherwise specified, $M P$ myeloproliferative, $C O P D$ chronic obstructive pulmonary disease, NHL non-Hodgkin's lymphoma, ECOG Eastern Cooperative Oncology Group

${ }^{\mathrm{a}}$ If a patient fulfilled criteria for more than one WHO category, weighting was performed as follows: t-AML $>$ AML-RCA $>$ AML-MRF

${ }^{\mathrm{b}}$ Amounts to $>100 \%$ due to multiple choice nature

${ }^{\mathrm{c}}$ Includes the following structural abnormalities: inversion $16, \mathrm{t}(8 ; 21)$, $\mathrm{t}(15 ; 17), \mathrm{t}(9 ; 11), \mathrm{t}(6 ; 9), \mathrm{t}(1 ; 22)$

${ }^{\mathrm{d}}$ Includes mutations in FLT3, NPM1, and/or CEBP $\alpha$

${ }^{\mathrm{e}}$ Includes arrhythmia (atrial fibrillation or flutter, sick sinus syndrome, or ventricular arrhythmias), coronary artery disease, coronary heart disease, myocardial infarction or ejection fraction $\leq 50 \%$, and/or valvular heart disease (except mitral valve prolapse)

${ }^{\mathrm{f}}$ Includes monoclonal gammopathy of unknown significance, multiple myeloma, low-grade NHL, high-grade NHL, M. Hodgkin, Burkitt's lymphoma, chronic myeloid leukemia, hypereosinophilic syndrome, chronic myeloproliferative diseases, and others

${ }^{\mathrm{g}}$ BM blast count was $<20 \%$, in those patients with established AML who were refractory to -or had no CR after-conventional chemotherapy or allogeneic stem cell transplantation

${ }^{\mathrm{h}}$ Defined as patients without prior disease modifying treatment (i.e., growth factors and iron chelation were allowed)

concerns with frailty and potential toxicity, and due to logistic reasons for patients living far away from the hospital. Azacitidine treatment dose was modified during treatment in $18 \%$ of patients: dose reductions occurred due to an adverse 
event (15\%) or due to patient's/physicians wish (2\%); dose escalation was performed in $1 \%$ of patients. Dose reductions were performed in $32 \%$ of responding patients (prior to best response $(13 \%)$, at best response $(3 \%)$, or after best response $(15 \%))$.

Concomitant treatment and best supportive care measures

Erythropoietin-stimulating agents (ESA) $(2.4 \%)$, iron chelation treatment (ICT) $(2.3 \%)$, and G-CSF $(18.4 \%)$ were given in parallel to azacitidine when deemed necessary by the treating physician.

\section{Response}

Overall response, defined as $\mathrm{CR}, \mathrm{mCR}, \mathrm{PR}$, and $\mathrm{HI}$, was documented in $48 \%$ of the total intention-to-treat (ITT) cohort and in $72 \%$ of patients evaluable according to MDS-IWG2006 response criteria [17] (i.e., had received $>2$ cycles of azacitidine); HI was documented in $40 \%$ (ITT) and $72 \%$ (evaluable according to IWG, i.e., had received $>2$ cycles of azacitidine), respectively; $\mathrm{CR} / \mathrm{mCR}$ was achieved in $17 \%$ of the ITT cohort and in $28 \%$ of patients in whom a BM aspirate/ biopsy was performed (Supplemental Table 2).

The median number of cycles received by responding patients was 8.5 (range 1-37), and 2 (range 1-28) in nonresponders (included patients with SD). Of note, the distribution of applied schedules as well as the median and mean azacitidine dosages/cycle did not differ between responders and non-responders.

Time to response and response deepening

Median time to first response was 3.0 months. First response occurred after 3, 4, and 5 cycles in 58, 79, and $88 \%$ of responding patients, respectively, but could be observed as late as cycle 16 in patients with stable disease who were kept on therapy. First response was best response in 99/144 patients (69 \%). Median response duration was 3.4 (range 0.3-33.0) months. Further deepening of response after first response (i.e., achievement of BM blast reduction in terms of $\mathrm{mCR} /$ $\mathrm{CR} / \mathrm{PR}$ after $\mathrm{HI})$ was seen in 45/144 (31\%) of responders. Best response was reached by cycle 9 in $94 \%$, but could be observed as late as cycle 21 . Median time from first to best response was 3.5 (range 0.8-21.5)months.

Toxicity and adverse events

A total of 1.031 adverse events (AE) were documented in 2.013 azacitidine cycles. Overall, $24 \%$ of all AE and $20 \%$ of grade 3-4 (G3-4) AE were attributed to azacitidine (Supplemental Table 3). Of all AE, $22 \%$ resulted in hospitalization and $9 \%$ resulted in death. Most $\mathrm{AE}$ had no consequence for azacitidine treatment (66\%). Dose reduction (5\%), treatment pause $(11 \%)$, prolongation of azacitidine cycle duration $>28$ days $(7 \%)$, and/or termination of azacitidine treatment $(11 \%)$ were not commonly necessary.

G3-4 hematologic toxicity occurred in 48 \%: G3-4 neutropenia, thrombocytopenia, and anemia were documented in 35 , 30 , and $28 \%$ of patients, respectively; clinically relevant bleeding events were noted in $12 \%$ of patients (Table 3 ). Non-hematologic toxicity was usually mild, the most common AE being fatigue (39\%), gastrointestinal (38\%), unspecified pain (30\%), and injection site reactions (22\%). Infectious complications of any grade were documented in $63 \%$, febrile neutropenia in $19 \%$ (Table 3). G3-4 infectious events occurred in $33 \%$ and were dominated by pulmonary infections, sepsis, and fever of unknown origin. Hospital admission was required in 173/423 (41\%) and transfer to an intensive care unit was necessary in $3 \%$ of total infectious events. Treatment with G-CSF, antibiotics, antifungals, and/or virostatics occurred in $18,86,22$, and $14 \%$, respectively.

A total of 47 non-hematologic G3-4 events occurred in 33 patients (11\%): 39 (83\%) of these grade 3-4 events occurred in the cardiac system: left ventricular output failure $(n=23)$, arrhythmia $(n=7)$, hypertension $(n=5)$, myocardial infarction $(n=3)$, angina pectoris $(n=1)$. In 20/33 (61\%) patients experiencing cardiac G3-4 events, pre-existing coronary artery disease, reduced cardiac function, arrhythmias, and/or valvular heart disease were documented prior to azacitidine treatment and worsening was not thought to be azacitidinerelated.

Overall survival and potential prognostic parameters

Median OS was 9.6 (95 \% CI 8.53-10.7)months as from initiation of treatment with azacitidine in the entire cohort. Median progression-free survival in responding patients was $9.1(0.9-39.9)$ months. Progression defining events were death due to any reason, disease progression, disease relapse after response, and/or new cytogenetic aberration/clonal evolution. Median OS was 16.1 months for responders (defined as CR/ $\mathrm{mCR} / \mathrm{PR} / \mathrm{HI}$ ) and 3.7 months for non-responders. Median time from first diagnosis to treatment start with azacitidine for untreated $(n=139)$ versus pre-treated with diseasemodifying treatment $(n=163)$ patients was 0.6 and 7.1 months, respectively. Median time from azacitidine treatment stop to death was 1.9 months in the entire cohort. Reasons for cessation of azacitidine in patients receiving $\leq 2$ cycles of azacitidine $(n=101,33.4 \%)$ were death $(n=48)$, disease progression $(n=20)$, patient's wish $(n=9)$, toxicity or recurrent infectious complications $(n=5)$, allo-SCT $(n=2)$, and others ( $n=13$ ); 41/101 receiving $\leq 2$ cycles died within 1 month of treatment termination, and a further 35 died within 6 months.

In line with our previous results [8], the following baseline factors did not significantly affect overall survival: gender, age 
Table 3 Specific adverse events ${ }^{\mathrm{a}}$

\begin{tabular}{|c|c|c|c|}
\hline Variable & Grade & $\begin{array}{l}\text { No. of patients, } \\
(\%)\end{array}$ & $\begin{array}{l}\text { No. of total } \\
\text { events }\end{array}$ \\
\hline $\begin{array}{l}\text { Hematologic } \\
\text { toxicity }\end{array}$ & G3-4 & $145(48.0)$ & 330 \\
\hline Thrombopenia & G3-4 & $91(30.1)$ & 195 \\
\hline Neutropenia & G3-4 & $105(34.8)$ & 223 \\
\hline Anemia & G3-4 & $84(27.8)$ & 177 \\
\hline Bleeding events & - & 35 (11.6) & 60 \\
\hline Febrile neutropenia & - & $56(18.5)$ & 95 \\
\hline \multirow{2}{*}{$\begin{array}{l}\text { Infectious } \\
\text { complications }\end{array}$} & G1-2 & $91(30.1)$ & 311 \\
\hline & G3-4 & $100(33.1)$ & 112 \\
\hline \multicolumn{4}{|c|}{ Non-hematologic toxicity } \\
\hline \multirow[t]{2}{*}{ Liver } & G1-2 & $2(0.7)$ & 3 \\
\hline & G3-4 & $2(0.7)$ & 2 \\
\hline \multirow[t]{2}{*}{ Kidney } & G1-2 & $12(4.0)$ & 12 \\
\hline & G3-4 & $3(1.0)$ & 3 \\
\hline \multirow[t]{2}{*}{ Heart $^{\mathrm{c}}$} & G1-2 & $8(2.6)$ & 14 \\
\hline & G3-4 & $29(9.6)$ & 34 \\
\hline \multirow[t]{2}{*}{ Blood pressure } & G1-2 & $3(1.0)$ & 3 \\
\hline & G3-4 & $5(1.7)$ & 5 \\
\hline \multirow[t]{2}{*}{ Metabolic } & G1-2 & $4(1.3)$ & 4 \\
\hline & G3-4 & $0(0.0)$ & 0 \\
\hline \multirow[t]{2}{*}{ Thromboembolic } & G1-2 & $11(3.6)$ & 12 \\
\hline & G3-4 & $2(0.7)$ & 2 \\
\hline \multirow[t]{2}{*}{ Neurologic } & G1-2 & $19(6.3)$ & 26 \\
\hline & G3-4 & $2(0.7)$ & 2 \\
\hline \multirow[t]{2}{*}{ Nausea } & G1-2 & $33(10.9)$ & 46 \\
\hline & G3-4 & $1(0.3)$ & 1 \\
\hline \multirow[t]{2}{*}{ Vomiting } & G1-2 & $9(3.0)$ & 12 \\
\hline & G3-4 & $0(0.0)$ & 0 \\
\hline \multirow[t]{2}{*}{ Constipation } & G1-2 & $21(7.0)$ & 28 \\
\hline & G3-4 & $1(0.3)$ & 1 \\
\hline \multirow[t]{2}{*}{ Diarrhea } & G1-2 & $26(8.6)$ & 35 \\
\hline & G3-4 & $0(0.0)$ & 0 \\
\hline \multirow{2}{*}{$\begin{array}{l}\text { Gastrointestinal, } \\
\text { others }\end{array}$} & G1-2 & $24(7.9)$ & 31 \\
\hline & G3-4 & $0(0.0)$ & 0 \\
\hline \multirow{2}{*}{$\begin{array}{l}\text { Injection site } \\
\text { reaction }\end{array}$} & G1-2 & $64(21.2)$ & 123 \\
\hline & G3-4 & $2(0.7)$ & 2 \\
\hline \multirow[t]{3}{*}{ Fatigue } & Relieved by rest & $46(15.2)$ & 89 \\
\hline & $\begin{array}{l}\text { Not relieved by } \\
\text { rest }\end{array}$ & 36 (11.9) & 63 \\
\hline & $\begin{array}{l}\text { Limiting self } \\
\text { care }\end{array}$ & 37 (12.3) & 42 \\
\hline \multirow[t]{3}{*}{ Pain } & Mild & $43(14.2)$ & 82 \\
\hline & Moderate & $39(12.9)$ & 51 \\
\hline & Severe & $9(3.0)$ & 9 \\
\hline Surgery & Elective & $19(6.3)$ & 23 \\
\hline
\end{tabular}

Table 3 (continued)

\begin{tabular}{llll}
\hline Variable & Grade & $\begin{array}{l}\text { No. of patients, } \\
(\%)\end{array}$ & $\begin{array}{l}\text { No. of total } \\
\text { events }\end{array}$ \\
\hline \multirow{3}{*}{ Fall } & Emergency & $10(3.3)$ & 11 \\
& Total & $26(8.6)$ & 29 \\
& With fracture & $10(3.3)$ & 11 \\
& With & $11(3.6)$ & 11 \\
\multirow{2}{*}{ Novel solid tumor } & Yes & $3(1.0)$ & 3 \\
\hline
\end{tabular}

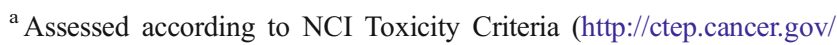
protocolDevelopment/electronic_applications/ctc.htm) and Common Terminology Criteria for AE (CTCAEv.4) (http://evs.nci.nih.gov/ftp1/ CTCAE/About.html)

${ }^{\mathrm{b}}$ Grade 3-4 cytopenias reported, are those that were documented as adverse events, and thus felt to be a worsening of pre-existing cytopenia by the respective treating physicians

${ }^{\mathrm{c}}$ Reported cardiac AE were left ventricular output failure $(n=23)$, arrhythmia $(n=7)$, hypertension $(n=5)$, myocardial infarction $(n=3)$, angina pectoris $(n=1)$

$<\geq 75$, age $<\geq 80$, WHO-AML-type, WBC count $<\geq 10 \mathrm{G} /$, WBC count $<>15 \mathrm{G} / \mathrm{l}$, WBC count $<>\geq 30 \mathrm{G} / \mathrm{l}$, neutrophil count $<1,000 / \mu 1$, lymphocyte count $<2,000 / \mu 1$, RBC-TD, BM blast count $\leq 30 />30 \%$ (irrespective of whether the whole cohort or only patients treated with azacitidine first line were analyzed), serum erythropoietin level, as well as prior treatment with ESA, G-CSF, iron chelators, low-dose Ara-C, or hydroxyurea (Supplemental Table 4 and Fig. 1a-h). When looking at responding patients only, WHO-AML type, WBC count, and treatment according to EMA label had no significant effect on survival (Supplemental Table 4).

Time-dependent factors that did not affect overall survival include the following: EMA target dose $(p=0.213)$, treatment schedule, dose/cycle, and platelet-doubling after one cycle (Supplemental Table 4). The following toxicity and adverse eventsrelated factors had no effect on overall survival: bleeding events, febrile neutropenia, surgery, non-hematologic toxicity, falls, and pain due to any reason (Supplemental Tables 1 and 4).

In multivariate analysis, the following baseline factors remained independent adverse predictors for OS: LDH $>225 \mathrm{U} / 1, \mathrm{ECOG} \geq 2$, number of comorbidities (as predefined by the HCT-CI [21]) $>3$, and monosomal karyotype. The following treatment-related factors that remained independent predictors for OS in multivariate analysis were as follows: AZA first-line treatment, hematologic improvement, and further deepening of response after first response; best marrow response $(p=0.642)$ did not meet the 0.05 significance level for inclusion in the multivariate analysis; azacitidine pause due to adverse events was associated with longer OS in multivariate analysis; dose reduction due to adverse events $(p=0.051)$ and fatigue limiting self-care $(p=0.053)$ were borderline significant in multivariate analysis (Figs. 2 and 3, and Supplemental Table 5). 
Fig. 1 Kaplan-Meier curves of baseline factors that did not affect overall survival (OS). a Effect of bone marrow blast count on OS (total cohort). b Effect of bone marrow blast count on OS (AZA first line). $\mathbf{c}$ Effect of age on OS. d Effect of WHO-AML type on OS. e Effect of white blood cell (WBC) count on OS. f Effect of WBC $<\geq 15$ G/1 on OS. g Effect of achievement of EMA/FDAtarget dose on OS. $\mathbf{h}$ Effect of azacitidine (AZA) schedule: 5 vs. 7 days of azacitidine per cycle on OS

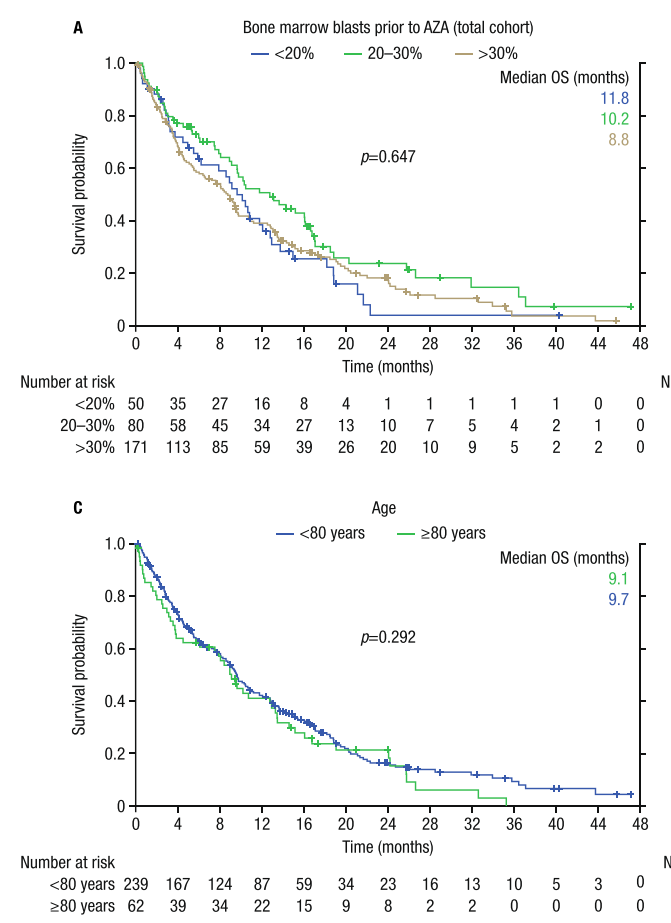

B Bone marrow blasts prior to AZA (AZA first-line)

$-20-30 \%->30 \%$

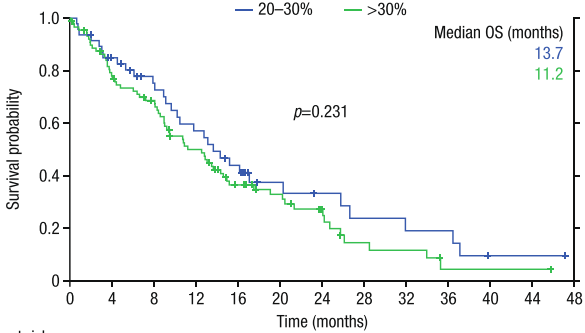

umber at risk

$\begin{array}{rlllllllllllll}20-30 \% & 47 & 37 & 30 & 22 & 17 & 10 & 7 & 5 & 5 & 4 & 2 & 1 & 0\end{array}$

Type of WHO-AML
D
1 -AML

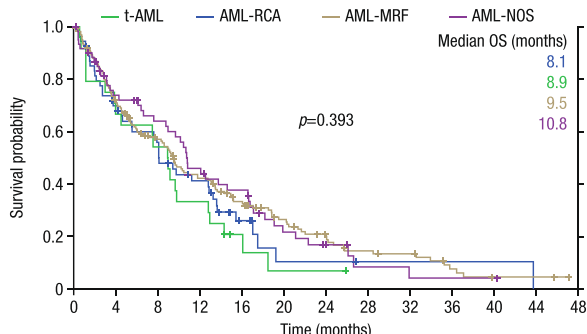

Number at risk

$\begin{array}{lllllllllllll}\text { t-AMLL } 24 & 17 & 13 & 8 & 3 & 1 & 1 & 1 & 0 & 0 & 0 & 0 & 0\end{array}$

$\begin{array}{lllllllllllll}\text { AML-RCA } 55 & 35 & 29 & 18 & 9 & 2 & 2 & 2 & 2 & 2 & 1 & 1 & 0\end{array}$ $\begin{array}{lccccccccccccc}\text { AML-MRF } & 162 & 113 & 83 & 59 & 44 & 30 & 21 & 13 & 11 & 7 & 3 & 2 & 0 \\ \text { AML-NOS } & 60 & 41 & 33 & 24 & 18 & 10 & 7 & 2 & 2 & 1 & 1 & 0 & 0\end{array}$
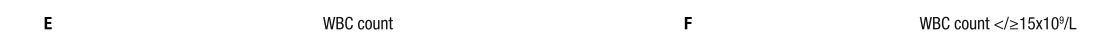$$
\mathbf{F}
$$$$
-<15 \times 10^{9 / L} \quad-\geq 15 \times 10^{9} / L
$$
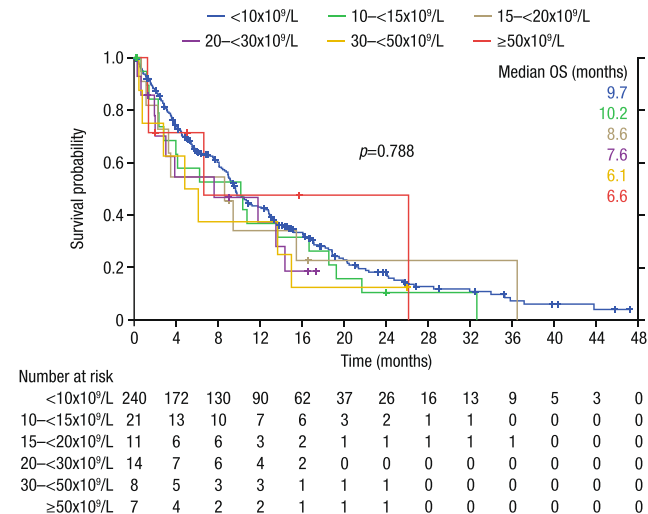

Number at risk
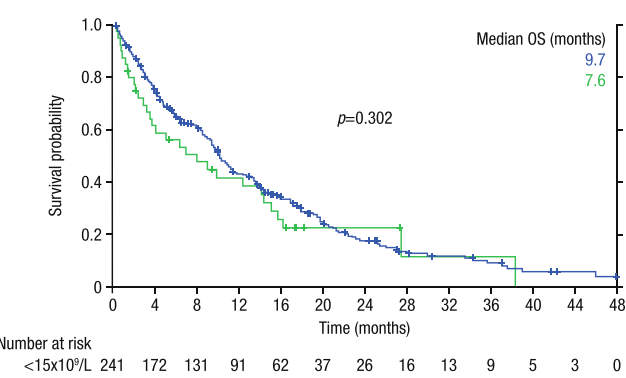
$215 \times 10^{\circ} / \mathrm{L}$
61 $\begin{array}{cccccccccccccc}20-<30 \times 10^{\circ} / L & 14 & 7 & 6 & 4 & 2 & 0 & 0 & 0 & 0 & 0 & 0 & 0 & 0 \\ 30-<50 \times 10^{\circ} / L & 8 & 5 & 3 & 3 & 1 & 1 & 1 & 0 & 0 & 0 & 0 & 0 & 0\end{array}$

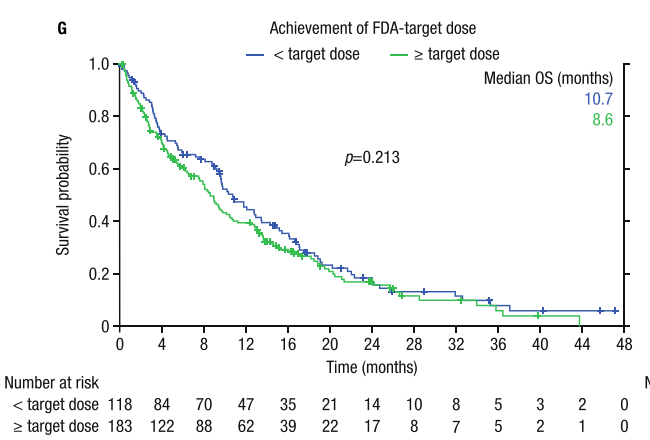

H
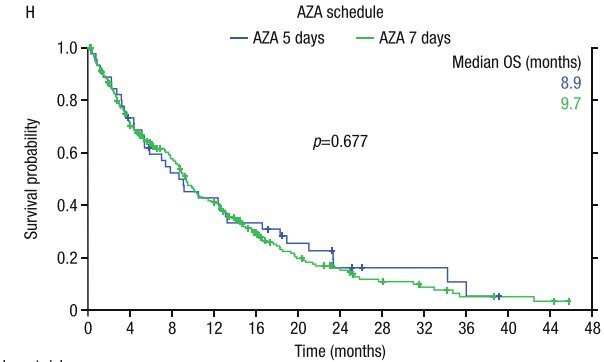

Number at risk

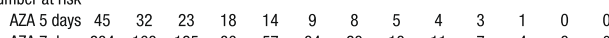

\section{Discussion}

This is the largest so far published number of azacitidinetreated WHO-AML patients, with the highest per capita coverage of AML patients in a nationwide registry, suggesting limited selection (Table 1, Supplemental Table 7). Data on the efficacy of azacitidine in AML with $>30 \%$ BM blasts are limited, and the drug can only be used off-label in these patients (Table 1 [4-14]). We report on 302 WHO-AML patients treated with azacitidine. This cohort included 172 
Fig. 2 Forrest plot of factors significantly influencing overall survival of azacitidine-treated AML patients $(n=302)$ in multivariate analysis

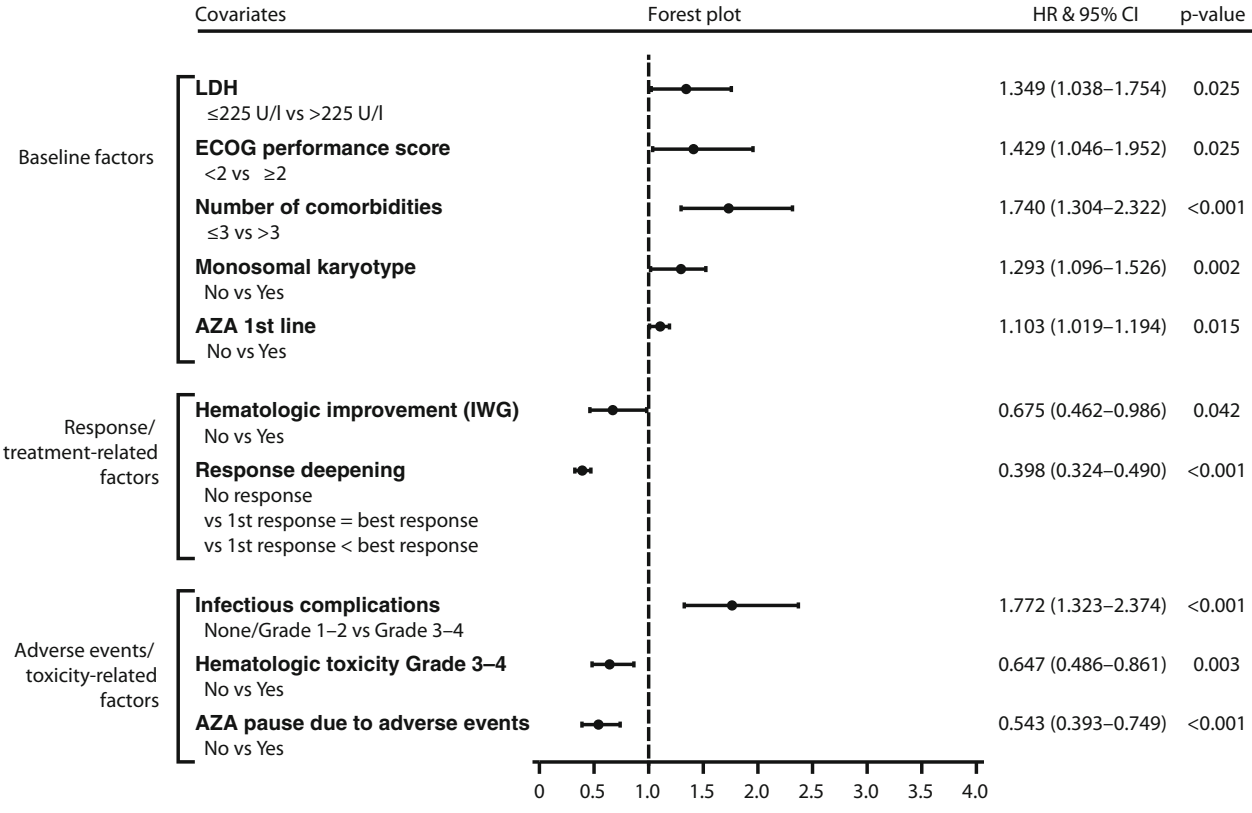

patients with $>30 \%$ BM blasts (Tables 1 and $4[6-8,12,14]$ ). The number of AML diagnoses per year, as well as the number of AML patients included in the respective year for Austria in general and Salzburg in particular, is presented in Supplemental Table 7 (data obtained from Statistics Austria (personal communication 23 May 2014), and Tumor Registry Salzburg (personal communication 26 May 2014)).

In order to exclude a potential time-dependent bias regarding both the choice of AML patients for treatment with azacitidine, as well as inclusion in the Austrian Azacitidine Registry, we compared all relevant baseline characteristics, treatment modalities, as well as response rates, and the occurrence of adverse events of our previously published cohort ( $n=155$; data cutoff 21 January 2012) [8] with the current cohort ( $n=302$, data cut off 21 January 2014). No significant difference could be found for any of these characteristics (Supplemental Table 6). With this nearly twice as large cohort, we confirm and validate the safety and efficacy of azacitidine in WHO-AML patients treated in a real-life setting. The observed median OS of 9.6 months and the high overall response rates (48\% ITT) seem remarkable, particularly since (i) the registry included many elderly (43\% $\geq 75$ years), comorbid (79\%), and/or pretreated patients (62\%); (ii) $33 \%$ of patients received $\leq 2$ cycles of azacitidine (reasons therefore listed in the "Results" section); (iii) $82 \%$ of our registry population would have been excluded from the AZA001 registration trial due to an estimated life expectancy $<3$ months, ECOG $>2$, t-AML, prior treatment, or planned allo-SCT $[3,4]$. If BM blast count $>30 \%$ is also taken into account, $93 \%$ would have been excluded.

Furthermore, virtually all of our prior results [8] regarding the statistical value of various factors on OS are confirmed by the present analysis. Slight discrepancies are mentioned below and in Table 4. In addition to the parameters looked at previously, we analyzed the putative prognostic effect of plateletdoubling after cycle 1, monosomal karyotype, and disease stabilization, as these factors have emerged to be of interest only recently $[12,13,22]$.

This is the first report to analyze the effect of plateletdoubling after cycle 1 on OS in AML patients treated with azacitidine. Statistical significance was not observed (Supplemental Table 4).

We confirm the recently introduced monosomal karyotype (MK) [23] to be the strongest adverse cytogenetic predictor for OS (even outperforming the categories "complex karyotype" and "MDS-related cytogenetic abnormalities" [22-24]) (Figs. 2 and 3a-b, Supplemental Table 5). We extend these findings to the new WHO classification and show that azacitidine cannot overcome the adverse outcome conferred by the presence of MK. Outcome in patients with MK is not only dismal with azacitidine but also with induction therapy and/or allogeneic stem cell transplantation [22]. Therefore, clinical trials are urgently needed for this patient subgroup.

We confirm our previous results [8] that a certain amount of aplasia induction seems necessary before response occurs, and that further deepening of response after first response (i.e., achievement of BM blast reduction in terms of $\mathrm{mCR} / \mathrm{CR} / \mathrm{PR}$ after $\mathrm{HI}$ ) translates into significantly longer OS (21.4 months), compared with patients for whom first response was best response (12.6 months) (Figs. 2 and 3e, Supplemental Table 5). This underlines the importance of continuing azacitidine treatment if or when HI occurs, even in the absence of marrow response. Patients experiencing HI had significantly longer OS than those who did not (16.1 vs. 4.5 months) (Fig. 3d and Supplemental Table 5). This is the first report to separately analyze $\mathrm{HI}$ and marrow response in multivariate 
Fig. 3 Kaplan-Meier curves of baseline factors that significantly affected overall survival (OS) in multivariate analysis. a Effect of monosomal karyotype (MK) on OS. $\mathbf{b}$ Effect of MK in comparison to complex karyotype on OS. c Effect of prior diseasemodifying treatment (i.e., azacitidine first-line no vs. yes) on OS. d Effect of hematologic improvement (HI) on OS. e Effect of response deepening (i.e., achievement of BM blast reduction in terms of $\mathrm{mCR} / \mathrm{CR} /$ PR after HI) on OS. f Overall survival by best response

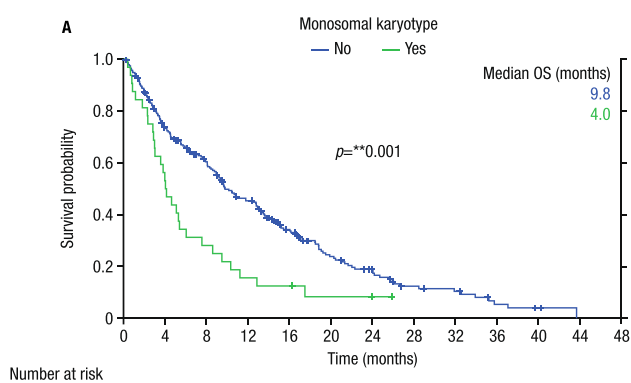

B Monosomal karyotype in comparison to complex karyotype - No - MK-only $\quad$ - MK and complex - Complex-only

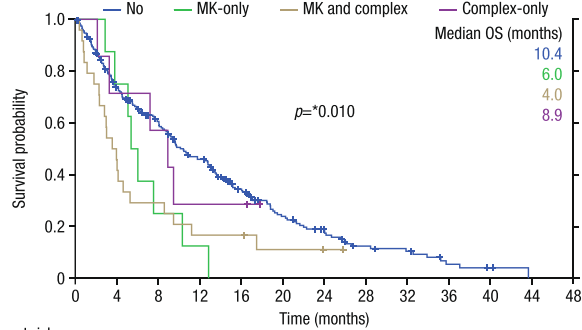
Number at risk Time (months)

$\begin{array}{ccccccccccccc}\text { No } 229 & 160 & 125 & 90 & 59 & 36 & 26 & 14 & 12 & 7 & 3 & 1 & 0 \\ \end{array}$ $\begin{array}{lllllllllllll}\text { No } 236 & 165 & 129 & 92 & 61 & 37 & 26 & 14 & 12 & 7 & 3 & 1\end{array}$ $\begin{array}{cccccccccccccc}\text { MK-only } & 8 & 6 & 2 & 1 & 0 & 0 & 0 & 0 & 0 & 0 & 0 & 0 & 0\end{array}$ $\begin{array}{cccccccccccccc}\text { KK and complex } & 24 & 12 & 7 & 4 & 4 & 2 & 2 & 1 & 0 & 0 & 0 & 0 & 0 \\ \text { Complex only } & 7 & 5 & 4 & 2 & 2 & 1 & 0 & 0 & 0 & 0 & 0 & 0 & 0\end{array}$

C

D Best hematologic improvement according to IWG (AML) Prior disease-modifying treatment

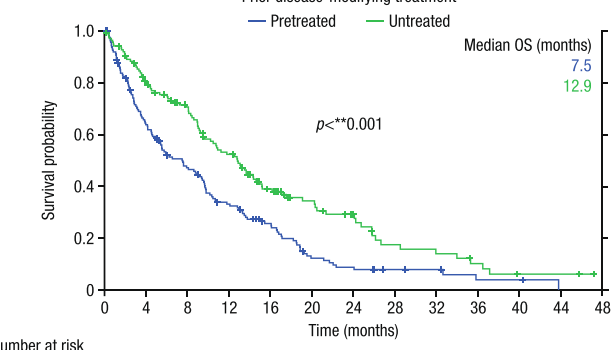
- No HI - Hl-platelets - $\mathrm{Hl}$-neutroph.

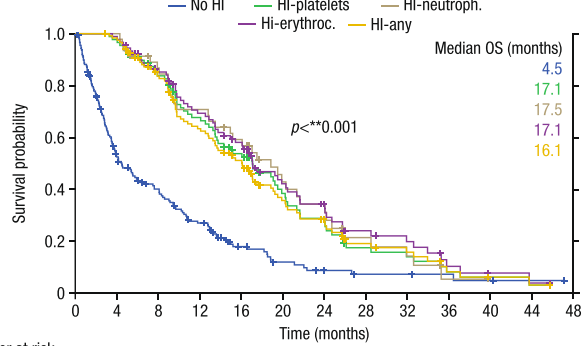
Number at risk

$\begin{array}{lllllllllllllllllllllllllllllll}\text { Untreated } & 138 & 107 & 88 & 63 & 43 & 28 & 21 & 10 & 9 & 6 & 3 & 2 & 0 & \text { HI-any } & 120 & 117 & 94 & 68 & 53 & 32 & 24 & 13 & 10 & 6 & 3 & 2 & 0\end{array}$

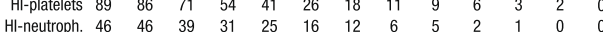

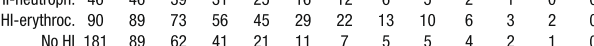

E

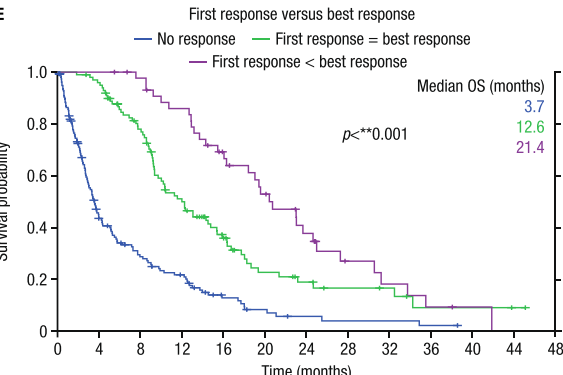

umber at risk

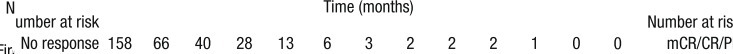

F Best response
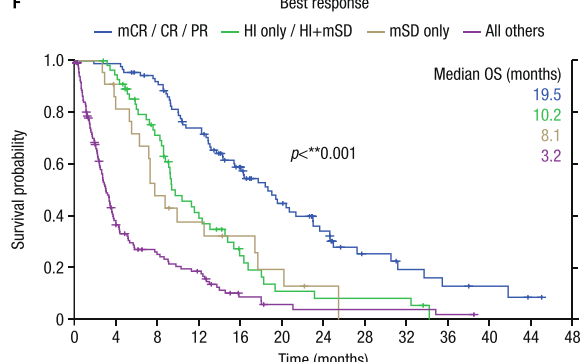

mer at risk Time (months)

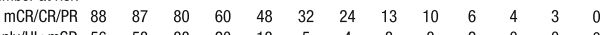

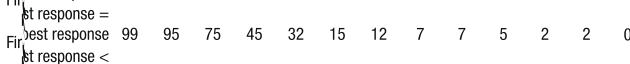

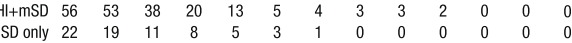

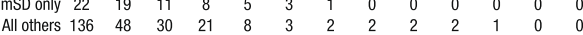

analysis. The former remained an independent prognostic factor for OS in multivariate analysis, whereas the latter did not (Fig. 2 and Supplemental Table 5). This seems of clinical relevance, as hematologic improvement is not generally considered sufficient response in AML patients. Very recently, the French group reported no survival benefit for patients achieving $\mathrm{HI}$ in addition to stable disease [12]. However, the authors state that (i) only those patients not achieving $\mathrm{mCR} / \mathrm{CR} / \mathrm{PR}$ were analyzed for HI; (ii) HI was only assessed when patients were evaluable for these parameters; (iii) it is not stated how many patients were not evaluable for HI or how SD was defined (i.e., marrow SD or hematologic SD). In our cohort, OS was significantly better for patients achieving $\mathrm{mCR} / \mathrm{CR} /$ PR with HI (20.5 months), followed by $\mathrm{mSD}$ with HI (18.9 months), mCR/CR/PR without HI (15.0 months), HI without $\mathrm{mSD}$ (9.7 months), mSD without HI (8.1 months), and not unexpectedly, OS was worst for patients with progressive disease or who received less than 3 cycles of azacitidine (3.2 months) (Supplemental Table 5). We thus confirm and extend the observations of the French group [12] as follows: It seems that achievement of any form of disease stabilization, be it $\mathrm{mSD}$ or $\mathrm{HI}$ alone, and especially the combination thereof (without the requirement of concomitant BM blast reduction, but with the minimal requirement of $\mathrm{mSD}$ ), is sufficient to confer a clinically relevant OS benefit. In our opinion and clinical experience, we thus consider disease stabilization to be sufficient "response" to continue treatment with azacitidine, although we are aware of the fact that this is currently not regarded as a standard form of response assessment in AML (Fig. 3f). In our experience, disease stabilization is lost rapidly once treatment with azacitidine is stopped (median time to death, 1.9 months). Thus bearing the lack of 
Table 4 Comparison of prognostic factors for OS in multivariate analysis (MVA) of all full publications on azacitidine treated AML patients

\begin{tabular}{|c|c|c|c|c|c|c|}
\hline Variable & Italy & Holland & Lausanne & France & Austria & Present study \\
\hline$n$ AML patients & 82 & 55 & $38^{\mathrm{a}}$ & 149 & 155 & 302 \\
\hline $\begin{array}{l}n \text { AML patients with }>30 \% \mathrm{BM} \\
\text { blasts }\end{array}$ & 49 & 17 & 29 & 87 & 98 & 172 \\
\hline \multicolumn{7}{|l|}{ Prognostic factors for OS } \\
\hline Age & \multirow{18}{*}{$\begin{array}{l}\text { No MVA for OS } \\
\text { performed }\end{array}$} & ND & No & No & No & No \\
\hline Gender & & ND & No & No & No & No \\
\hline Cytogenetic risk group & & Yes $(* * p=0.001)^{\mathrm{b}, \mathrm{c}}$ & $\mathrm{No}^{\mathrm{d}}$ & Yes $(* * p<0.001)^{\mathrm{b}}$ & $\mathrm{No}^{\mathrm{b}}$ & $\mathrm{No}^{\mathrm{b}}$ \\
\hline Monosomal karyotype & & ND & ND & $\mathrm{ND}$ & ND & $\operatorname{Yes}(* * p=0.002)$ \\
\hline $\mathrm{WBC}<\geq 15 \mathrm{~g} / \mathrm{l}$ & & Yes $(* * p=0.003)^{\mathrm{e}}$ & ND & Yes $(* * p=0.001)$ & No & No \\
\hline $\mathrm{LDH}<\geq 225 \mathrm{IU} / 1$ & & No & ND & $\mathrm{ND}$ & No & Yes $(* p=0.025)$ \\
\hline ECOG performance score $<>2$ & & Yes $(* * p=0.006)^{\mathrm{f}}$ & ND & Yes $\left({ }^{* *} p=0.006\right)$ & Yes $\left({ }^{*} p=0.040\right)$ & Yes $(* p=0.025)$ \\
\hline Number of comorbidities $<1 \geq 4$ & & $\mathrm{ND}$ & ND & $\mathrm{ND}$ & No $(p=0.086)$ & Yes $(* * p<0.001)$ \\
\hline AZA first line & & ND & ND & ND & ND & Yes $(* p=0.015)$ \\
\hline AML type ${ }^{g}$ & & No & $\mathrm{No}^{\mathrm{h}}$ & No & No & No \\
\hline BM blasts $<>\geq 30 \%$ & & No & No & No & No & No \\
\hline PB blasts $<\geq 0 \%$ & & No & $\mathrm{No}^{\mathrm{i}}$ & ND & Yes $(* p=0.040)$ & No \\
\hline Transfusion dependence & & No & Yes $(* * p=0.009)^{j}$ & ND & No & No \\
\hline RBC-TI & & ND & & ND & $\operatorname{Yes}(* * p<0.001)$ & Yes $(* p=0.042)$ \\
\hline PLT-TI & & ND & No & ND & & \\
\hline Hematologic improvement & & ND & ND & ND & & \\
\hline AZA schedule (5 vs. 7 days) & & ND & ND & No & No & No \\
\hline AZA dose $\left(<=75 \mathrm{mg} / \mathrm{m}^{2} /\right.$ day $)$ & & ND & ND & No & No & No \\
\hline
\end{tabular}

${ }^{a}$ Baseline characteristics were reported from 52 patients, but only 38 were evaluated for response

${ }^{\mathrm{b}}$ Defined according to MRC classification

${ }^{\mathrm{c}}$ Only the poor risk-group predicted OS, the good vs. intermediate risk group did not $(p=0.91)$

${ }^{\mathrm{d}}$ Defined according to the HOVON classification

${ }^{\mathrm{e}}$ Cutoff, $<>10 \mathrm{G} / 1$; however, this variable was not significant in univariate analysis $(p=0.11)$

${ }^{\mathrm{f}}$ According to WHO performance score

${ }^{\mathrm{g}}$ Primary AML, post-MDS, post-MPN, refractory/relapsed disease or therapy-related AML

${ }^{\mathrm{h}}$ Only therapy-related AML ( $n=10$ patients) had an impact when looked at separately $\left({ }^{* *} p<0.001\right)$, whereas AML type did not $(p=0.086)$

${ }^{\mathrm{i}}$ PB blast cut off of $\geq 20 \%$ used

${ }^{\mathrm{j}}$ Not reported on separately, i.e., patients that were transfusion independent at baseline, or who achieved RBC-TI during treatment were grouped together

therapeutic alternatives in mind, we continue azacitidine treatment until overt clinical disease progression.

In order to facilitate the comparison of our previous and current results with data obtained from much smaller cohorts, we provide an in-depth comparison of all published multivariate analyses on putative prognostic factors for OS of WHOAML patients treated with azacitidine (including results from the present study) (Table 4). Only one baseline factor remained a significant adverse predictor for OS in all multivariate analysis (4/4) in which baseline factors were analyzed, namely ECOG/WHO performance score (Table 4). Thus, the ability of patients to function in everyday life seems to be the most important predictor of OS in elderly AML patients treated with azacitidine. In line with this, the absolute number of comorbidities, which was borderline significant in our previously published smaller cohort of AML patients $(n=$
155) [8], was confirmed to be an independent adverse predictor of OS in our larger present cohort $(n=302)$ (Fig. 2, Table 4, and Supplemental Table 5).

Although not unexpected, we show for the first time in multivariate analysis - thus confirming our clinical experience and notion - that prior disease-modifying treatment is an adverse predictor of OS for AML patients treated with azacitidine. In multivariate analysis, patients receiving azacitidine first line had significantly longer overall survival than pretreated patients (12.9 vs. 7.5 months) (Figs. 2 and 3c, Supplemental Table 5).

Age, gender, AML type, and transfusion dependence prior to azacitidine had no significant effect on OS in all reports in which these factors were analyzed (Table 4, Supplemental Table 4, and Fig. 1c, d). As azacitidine is still not approved for the treatment of AML patients with $>30 \%$ BM blasts, we 
were particularly interested to see that the percentage of BM blasts had no significant effect on OS in this off-label treated patient subgroup $(n=172)$, which is in line with observations by others with smaller patient numbers (Fig. 1a, b, Table 4, and Supplemental Table 4).

The present report confirms that WHO-AML type does not seem to adversely predict OS. We conclude that AML patients with MDS-related features, or therapy-related AML, should not be precluded from treatment with azacitidine. The latter seems clinically relevant, especially in light of the fact that these AML subgroups are generally considered to have worse prognosis and to be less responsive to conventional chemotherapy.

The prognostic relevance of elevated $\mathrm{WBC} \geq 15 \mathrm{G} / 1$ currently remains unclear and conflicting results exist (Table 4). Several statistical issues remain open in the two publications describing a significant adverse effect of $W B C \geq 15 \mathrm{G} / 1$ on OS in multivariate analysis: (i) in the Dutch cohort, this variable was not significant in univariate analysis $(p=0.11)$, but was nevertheless included in multivariate analysis. Furthermore, $95 \%$ CI were not given for multivariate results [14]; (ii) the univariate $p$ values used for entry of the variables into the multivariate model $(p<0.15$ [14] and $p<0.85$ [25], respectively) were less stringent than in the present publication $(p<0.05)$, which could not find an adverse effect of elevated WBC, irrespective of which cutoff value was used $(<\geq 10,<1$ $\geq 15$, or $<\geq 30 \mathrm{G} / 1$ (Supplemental Table 4 and Fig. 1e, f)).

Neither azacitidine schedule ( 5 vs. 7 days) nor dosage $(<v s$. $=75 \mathrm{mg} / \mathrm{m}^{2} /$ day) had a significant effect on OS in $3 / 3$ reports in which these factors were analyzed (Table 4, Supplemental Table 4, and Fig. 1g, h). Thus, alternative schedules and dosages seem safe and without loss of efficacy, and receiving the drug regularly and continuously until overt clinical progression occurs is likely more relevant than the absolute dosage per day or number of days per cycle.

In conclusion, we confirm that azacitidine is safe and effective in elderly, comorbid AML patients treated in an everyday life setting, irrespective of BM blast count.

Acknowledgments The authors would like to thank Gudrun PlacherSorko, Paracelsus Medical University Salzburg, and Martina Mitrovic, Innsbruck Medical University, for helping with data entry in the eCRF. We would also like to thank Andrew Brittain, from the Knowledgepoint360 Group for the correct formatting of the figures. He had no influence on planning, writing, or interpreting the manuscript.

Funding The AAR is a Registry of the Arbeitsgemeinschaft Medikamentöse Tumortherapie' (AGMT) Study Group which served as the responsible sponsor and holds the full and exclusive rights on data. Financial support for the AGMT was received from Celgene. Celgene had no role in study design, data collection, data analysis, data interpretation, or writing of the manuscript.

Conflict of interest Consultant or advisory role: LP, Celgene, BristolMyers Squibb, Novartis; WS, Celgene; SB, Celgene; MP, Celgene,
Novartis; MG, Mundipharma; AL, Celgene; RS, Celgene; RG, BristolMyers-Squibb, Cephalon, Celgene.

Honoraria: LP, Celgene, Bristol-Myers Squibb, Novartis, AOP Orphan Pharmaceuticals; WS, Celgene, Novartis; SB, Mundipharma, Novartis, AOP Orphan Pharmaceuticals; MP, Celgene, Novartis, Janssen-Cilag; MG, Pfizer, Mundipharma; RS, Ratiopharm, Celgene; RG, Amgen, Eisai, Mundipharma, Merck, Janssen-Cilag, Genentech, Novartis, Astra-Zeneca, Cephalon, Boehringer-Ingelheim, Pfizer, Roche, Bristol-Myers Squibb, Sanofi Aventis.

Research funding: MG, Pfizer; RS, Ratiopharm, Novartis, Celgene; WS, Phadia; RG, GSK, Amgen, Genentech, Ratiopharm, Celgene, Pfizer, Mundipharma, Cephalon.

Open Access This article is distributed under the terms of the Creative Commons Attribution License which permits any use, distribution, and reproduction in any medium, provided the original author(s) and the source are credited.

\section{References}

1. Lowenberg B (2001) Prognostic factors in acute myeloid leukaemia. Best Pract Res Clin Haematol 14(1):65-75

2. Stone RM (2002) The difficult problem of acute myeloid leukemia in the older adult. CA Cancer J Clin 52(6):363-371

3. Fenaux P, Mufti GJ, Hellstrom-Lindberg E, Santini V, Finelli C, Giagounidis A et al (2009) Efficacy of azacitidine compared with that of conventional care regimens in the treatment of higher-risk myelodysplastic syndromes: a randomised, open-label, phase III study. Lancet Oncol 10(3):223-232

4. Fenaux P, Mufti GJ, Hellstrom-Lindberg E, Santini V, Gattermann N, Germing U et al (2010) Azacitidine prolongs overall survival compared with conventional care regimens in elderly patients with low bone marrow blast count acute myeloid leukemia. J Clin Oncol 28(4): $562-569$

5. Al Ali HK, Jaekel N, Junghanss C, Maschmeyer G, Krahl R, Cross M et al (2012) Azacitidine in patients with acute myeloid leukemia medically unfit for or resistant to chemotherapy: a multicenter phase I/II study. Leuk Lymphoma 53(1):110-117

6. Gavillet M, Noetzli J, Blum S, Duchosal MA, Spertini O, Lambert JF (2012) Transfusion independence and survival in patients with acute myeloid leukemia treated with 5-azacytidine. Haematologica 97(12): 1929-1931

7. Maurillo L, Venditti A, Spagnoli A, Gaidano G, Ferrero D, Oliva E et al (2012) Azacitidine for the treatment of patients with acute myeloid leukemia: report of 82 patients enrolled in an Italian compassionate program. Cancer 118(4):1014-1022

8. Pleyer L, Stauder R, Burgstaller S, Schreder M, Tinchon C, Pfeilstocker $M$ et al (2013) Azacitidine in patients with WHO-defined AMLresults of 155 patients from the Austrian Azacitidine Registry of the AGMT-Study Group. J Hematol Oncol 6(1):32

9. Silverman LR, McKenzie DR, Peterson BL, Holland JF, Backstrom JT, Beach CL et al (2006) Further analysis of trials with azacitidine in patients with myelodysplastic syndrome: studies 8421, 8921, and 9221 by the Cancer and Leukemia Group B. J Clin Oncol 24(24): 3895-3903

10. Sudan N, Rossetti JM, Shadduck RK, Latsko J, Lech JA, Kaplan RB et al (2006) Treatment of acute myelogenous leukemia with outpatient azacitidine. Cancer 107(8):1839-1843

11. Thepot S, Itzykson R, Seegers V, Raffoux E, Quesnel B, Chait Y et al (2010) Treatment of progression of Philadelphia negative myeloproliferative neoplasms to myelodysplastic syndrome or acute myeloid 
leukemia by azacitidine: a report on 54 cases on the behalf of the Groupe Francophone des Myelodysplasies. Blood 116(19):3735-3742

12. Thepot S, Itzykson R, Seegers V, Recher C, Raffoux E, Quesnel B et al (2014) Azacitidine in untreated acute myeloid leukemia. A report on 149 patients. Am J Hematol 89(4):410-416

13. van der Helm LH, Alhan C, Wijermans PW, van Marwijk KM, Schaafsma R, Biemond BJ et al (2011) Platelet doubling after the first azacitidine cycle is a promising predictor for response in myelodysplastic syndromes (MDS), chronic myelomonocytic leukaemia (CMML) and acute myeloid leukaemia (AML) patients in the Dutch azacitidine compassionate named patient programme. Br J Haematol 155(5):599-606

14. van der Helm LH, Veeger NJ, Kooy M, Beeker A, de Weerdt O, de Groot $\mathrm{M}$ et al (2013) Azacitidine results in comparable outcome in newly diagnosed AML patients with more or less than $30 \%$ bone marrow blasts. Leuk Res 37(8):877-882

15. Pleyer L, Germing U, Sperr WR, Linkesch W, Burgstaller S, Stauder $R$ et al (2014) Azacitidine in CMML: matched-pair analyses of dailylife patients reveal modest effects on clinical course and survival. Leuk Res 38(4):475-483

16. Cheson BD, Bennett JM, Kopecky KJ, Buchner T, Willman CL, Estey EH et al (2003) Revised recommendations of the International Working Group for diagnosis, standardization of response criteria, treatment outcomes, and reporting standards for therapeutic trials in acute myeloid leukemia. J Clin Oncol 21(24): 4642-4649

17. Cheson BD, Greenberg PL, Bennett JM, Lowenberg B, Wijermans PW, Nimer SD et al (2006) Clinical application and proposal for modification of the International Working Group (IWG) response criteria in myelodysplasia. Blood 108(2):419-425
18. Grimwade D, Walker H, Oliver F, Wheatley K, Harrison C, Harrison G et al (1998) The importance of diagnostic cytogenetics on outcome in AML: analysis of 1,612 patients entered into the MRC AML 10 trial. The Medical Research Council Adult and Children's Leukaemia Working Parties. Blood 92(7):2322-2333

19. Dombret H, Raffoux E, Gardin C (2008) Acute myeloid leukemia in the elderly. Semin Oncol 35(4):430-438

20. Greenberg P, Cox C, LeBeau MM, Fenaux P, Morel P, Sanz G et al (1997) International scoring system for evaluating prognosis in myelodysplastic syndromes. Blood 89(6):2079-2088

21. Sorror ML, Maris MB, Storb R, Baron F, Sandmaier BM, Maloney DG et al (2005) Hematopoietic cell transplantation (HCT)-specific comorbidity index: a new tool for risk assessment before allogeneic HCT. Blood 106(8):2912-2919

22. Kayser S, Zucknick M, Dohner K, Krauter J, Kohne CH, Horst HA et al (2012) Monosomal karyotype in adult acute myeloid leukemia: prognostic impact and outcome after different treatment strategies. Blood 119(2):551-558

23. Breems DA, Van Putten WL, De Greef GE, Zelderen-Bhola SL, Gerssen-Schoorl KB, Mellink CH et al (2008) Monosomal karyotype in acute myeloid leukemia: a better indicator of poor prognosis than a complex karyotype. J Clin Oncol 26(29):47914797

24. Breems DA, Lowenberg B (2011) Acute myeloid leukemia with monosomal karyotype at the far end of the unfavorable prognostic spectrum. Haematologica 96(4):491-493

25. Thepot S (2009) IRSVRCQBDJCTeal. Azacytidine (AZA) as first line therapy in AML: results of the French ATU Program. Blood 114(22):843 